Supporting Information for

\title{
Formation Mechanism of Multi-purpose Silica Nanocapsules
}

Michael Graham and Dmitry Shchukin

Stephenson Institute for Renewable Energy, University of Liverpool, Peach Street, Liverpool, UK, L69 7ZF

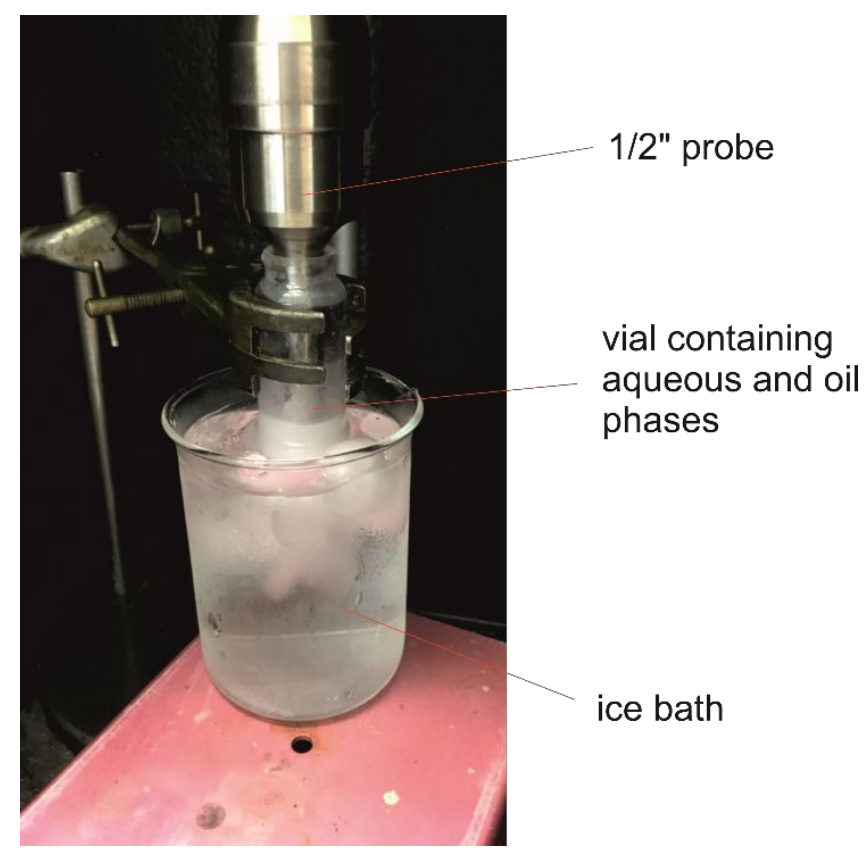

Figure S1. Photograph of the sonicator setup to produce Pickering emulsions. 


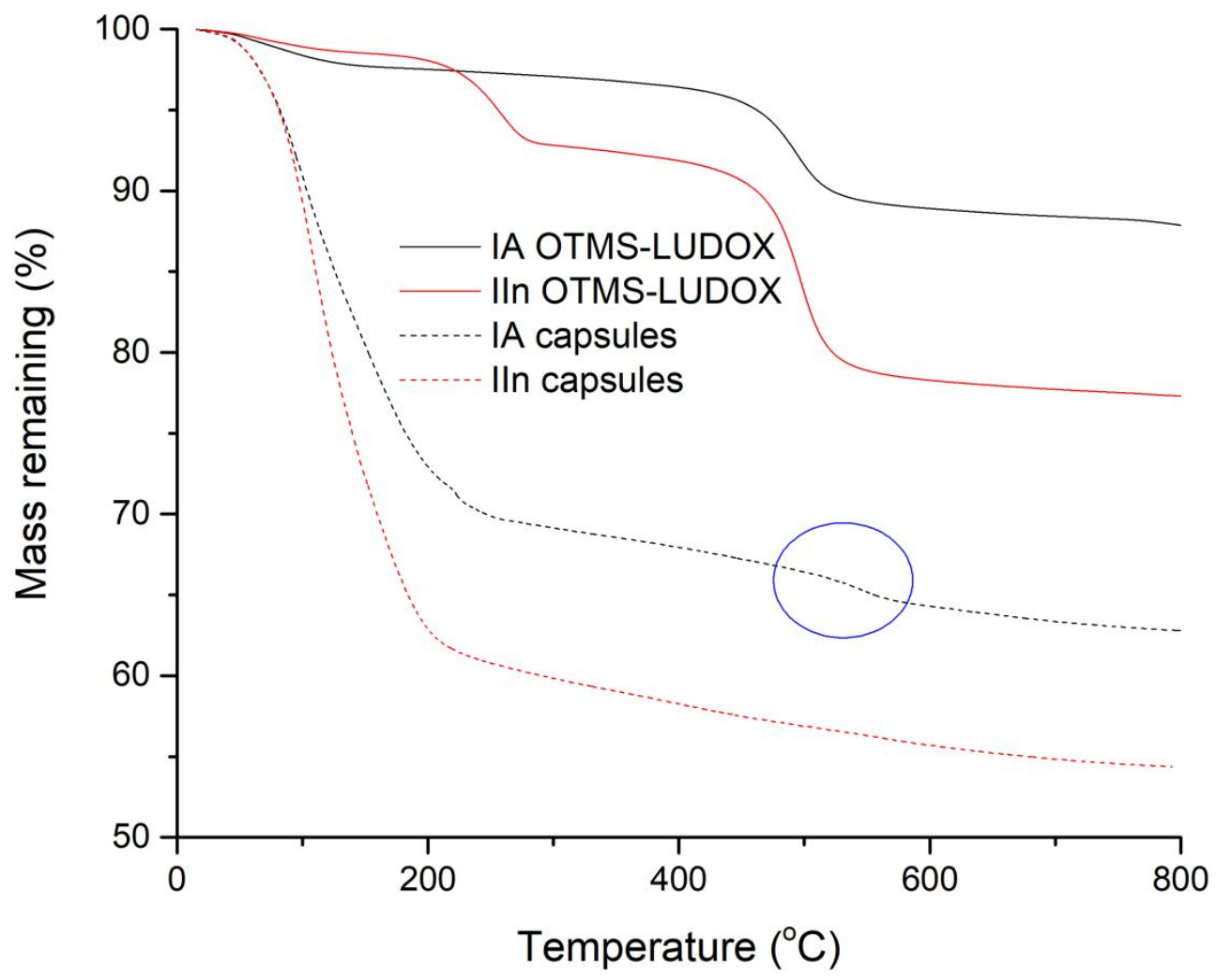

Figure S2. Comparison of capsules made with IA and IIn OTMS-LUDOX. Note the circled area, indicating the loss of OTMS groups from the IA capsules. This indicates the alkyl silane surface bonding in IA OTMS-LUDOX is very strong and can withstand ultrasonication during emulsion formation. This loss is not observed for the IIn capsules, due to the weakly bound OTMS already being lost from LUDOX particles during ultrasonication. IIn capsules also lose more mass overall, attributed to extra water being present in the larger capsules (IIn capsule diameter 2-6 $\mu \mathrm{m}$ vs 500 $\mathrm{nm}$ diameter of IA capsules). Interestingly, the OTMS is lost at a higher temperature from the IA capsules $\left(500-550^{\circ} \mathrm{C}\right)$ than from the IA OTMS-LUDOX particles themselves $\left(420-520^{\circ} \mathrm{C}\right)$. This is probably due to the incorporation of the particles into the robust shell. 


\section{Surface coverage of OTMS on LUDOX particles:}

Using TGA data in Fig $1 \mathrm{~g}$, we have estimated surface coverage of OTMS on IA and IIn OTMS-LUDOX particles. We make the following assumptions (i) OTMS functional groups are evenly distributed on the particle surface, which can be made as the reaction took place over $24 \mathrm{hr}$ in solution (ii) LUDOX density is unaffected by OTMS attachment (iii) The mass of all OTMS functional groups bound to the LUDOX surface is lost from $420-520^{\circ} \mathrm{C}$ during TGA - this is $7 \%$ mass ( 0.07 mass fraction) for IA OTMS-LUDOX and $14 \%$ (0.14 mass fraction) for Iln OTMS-LUDOX.

Adapted from 'Hydrophobic CuO Nanosheets Functionalized with Organic Adsorbates', He et al. 2018 (ref 47):

$\tau=M_{f} / \sigma$

where $\tau$ is surface coverage of functional group OTMS ( $g_{\text {отмs }} / \mathrm{m}^{2}$ ), $\mathrm{M}_{\mathrm{f}}$ is mass fraction of OTMS compared to the overall sample ( $\left.g_{\text {отмs }} / g_{\text {total }}\right)$, and $\sigma$ is specific surface area of the sample $\left(\mathrm{m}^{2} / \mathrm{g}_{\text {total }}\right)$. Using data from the manufacturer, surface area of LUDOX TMA is $140 \mathrm{~m}^{2} \cdot \mathrm{g}^{-1}$.

\section{IA OTMS-LUDOX}

$M_{f}=0.07$

$\sigma=140 \mathrm{~m}^{2} \cdot \mathrm{g}^{-1}$

$\tau=0.07 / 140=0.0005 \mathrm{~g} \cdot \mathrm{m}^{-2}=0.5 \mathrm{mg} \cdot \mathrm{m}^{-2}$

\section{IIn OTMS-LUDOX}

$M_{f}=0.14$

$\sigma=140 \mathrm{~m}^{2} \cdot \mathrm{g}^{-1}$

$\tau=0.14 / 140=0.001 \mathrm{~g} \cdot \mathrm{m}^{-2}=1 \mathrm{mg} \cdot \mathrm{m}^{-2}$

This data is consistent with observations in Figure 1 and Figure $S 2$ that the surface bonding of IA OTMS-LUDOX is stronger than that of IIn OTMS-LUDOX. There is likely $3 \mathrm{Si-O}$ bonds forming between OTMS and LUDOX in IA OTMS-LUDOX, while IIn OTMS-LUDOX is more likely to only form 1 or 2 Si-O bonds. Therefore, there are roughly 2 times more binding sites available on the IIn OTMS-LUDOX surface and hence $\tau$ is 2 times greater than IA OTMS-LUDOX.

Surface treatment with OTMS groups leads to highly hydrophobic particles with a water contact angle of $134^{\circ}$. Ref 47 reported a similar surface coverage to IA OTMS-LUDOX for adsorbed toluene $\left(0.44 \mathrm{mg} \cdot \mathrm{m}^{-2}\right)$ and obtained an identical contact angle with water. 


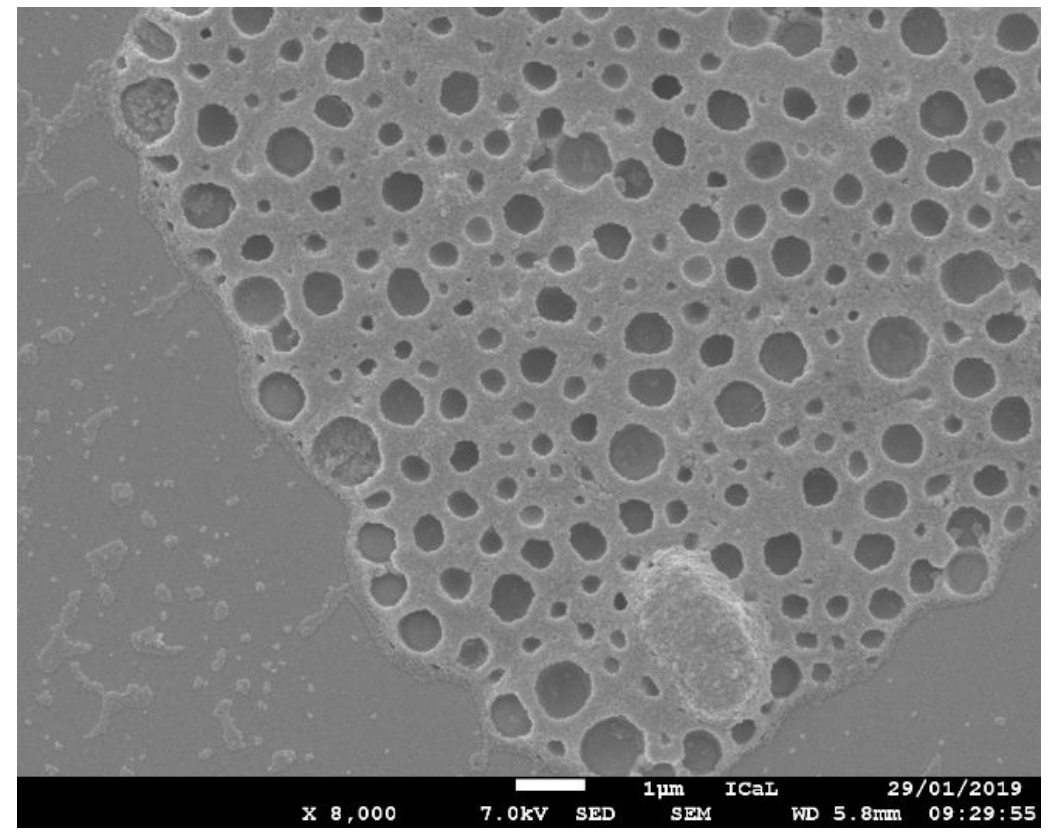

Figure S3. SEM image of a Pickering emulsion with no further silica shell added. Scale bar is $1 \mu \mathrm{m}$.

Figure S3 shows Pickering emulsions alone were not stable enough to be imaged. The 'holes' in the image are caused by collapsed emulsion droplets. This confirms an additional shell is required to fully stabilise the core material. 

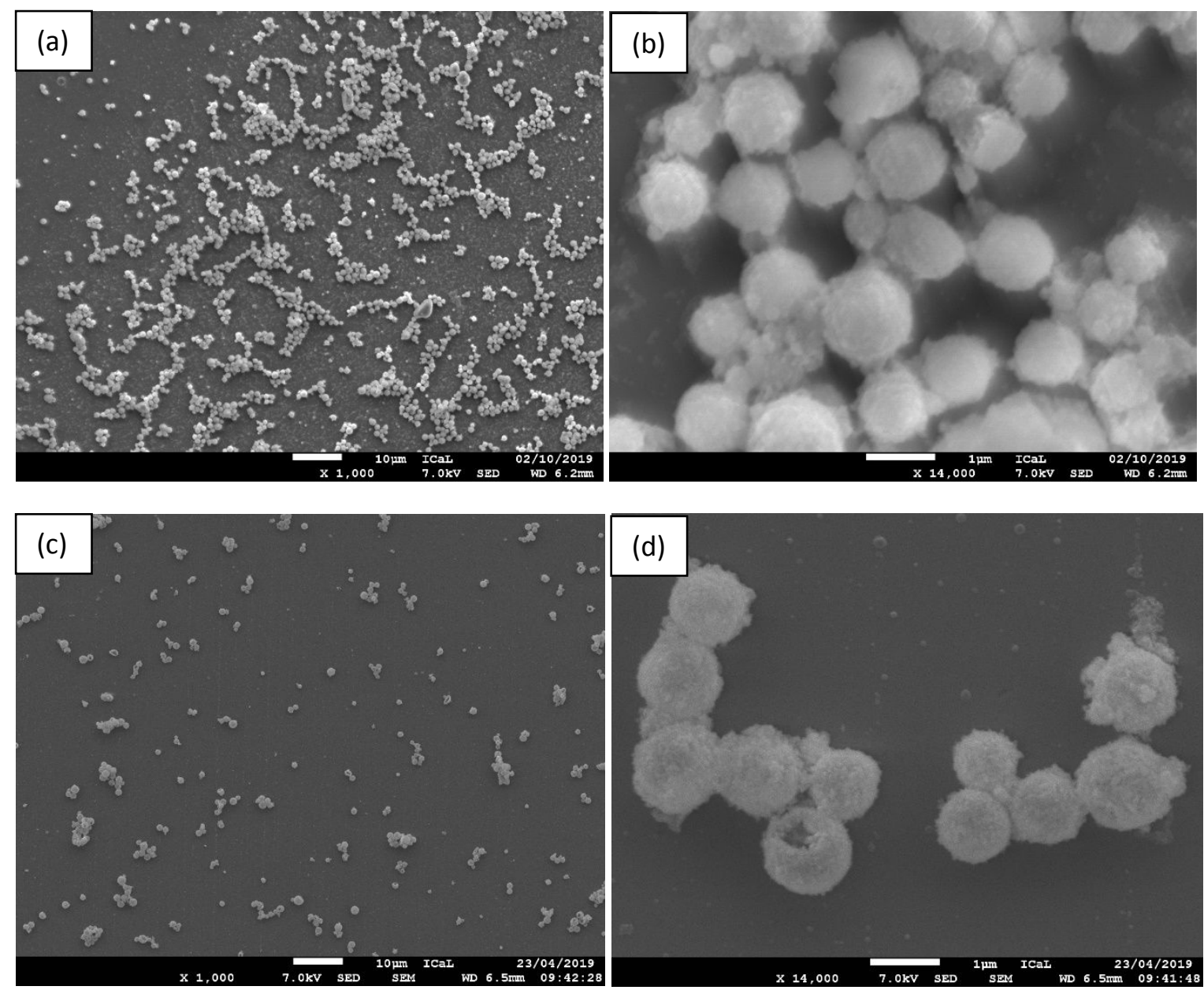

Figure S4. SEM images of RSS capsules formed with other silicates in place of TEOS. (a \& b) $1 \mathrm{~mL}$ tetramethyl orthosilicate (TMOS) with $1 \mathrm{~mL} \mathrm{HCl}$ as catalyst, (c \& d) $3 \mathrm{~mL}$ tetrabutyl orthosilicate (TBOS) with $2 \mathrm{~mL} \mathrm{HCl}$ as catalyst. All samples had $5 \% w t$ IA OTMS-LUDOX in cyclohexane as oil phase. Scale bars are $10 \mu \mathrm{m}$ for $a \& c, 1 \mu \mathrm{m}$ for $b \& d$.

Figure S4 demonstrates the versatility of our synthesis, as other silica precursors (TMOS and TBOS) can be used directly in place of TEOS. However, TEOS is more widely available, inexpensive and liberates a relatively non-toxic by-product upon condensation (ethanol). TMOS and TBOS liberate methanol and butanol respectively, which have increased toxicity to humans. 

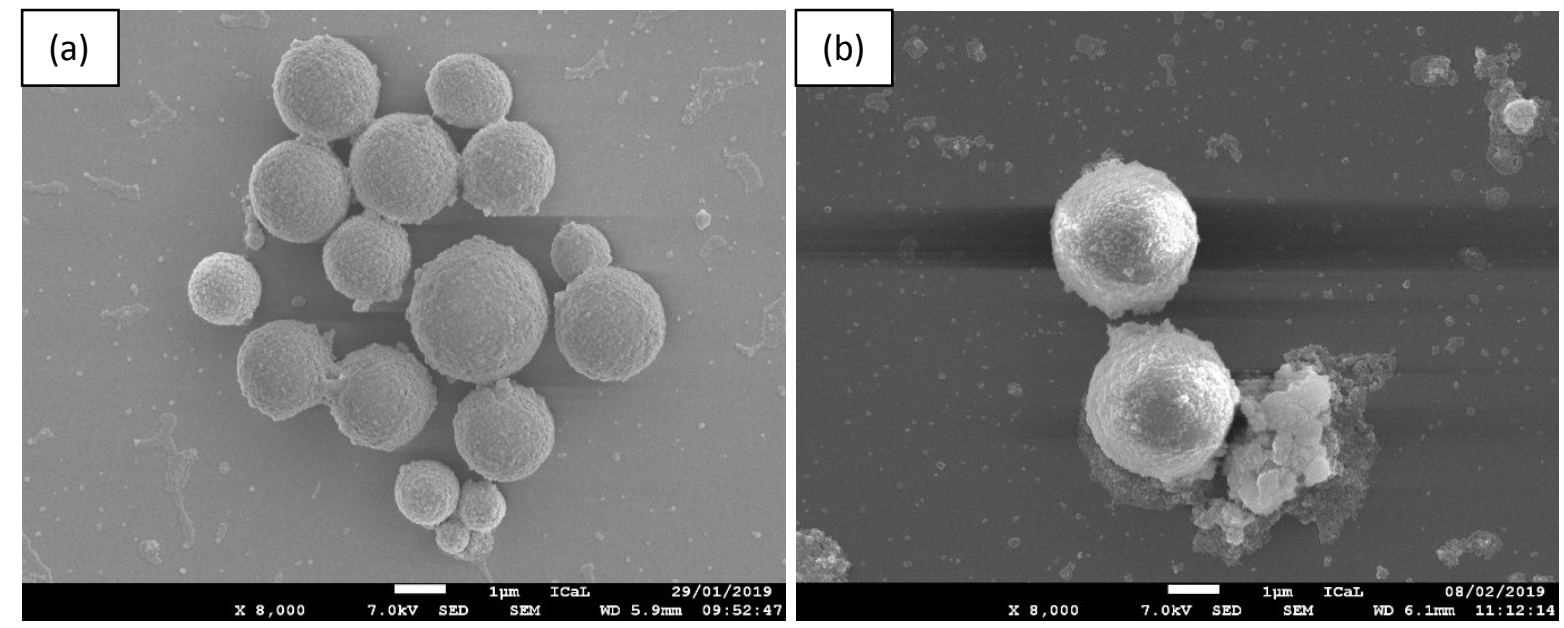

Figure S5. SEM images of capsules made with $5 \% \mathrm{wt} \mathrm{IA} \mathrm{OTMS-LUDOX} \mathrm{and} \mathrm{(a)} 3 \mathrm{~mL}$ TEOS and $1 \mathrm{~mL} \mathrm{HCl}$, (b) $3 \mathrm{~mL}$ and TEOS $3 \mathrm{~mL} \mathrm{HCl}$. Note the larger sizes compared to capsules prepared with $3 \mathrm{mLTEOS}$ and $2 \mathrm{~mL} \mathrm{HCl}$. Scale bars are $1 \mu \mathrm{m}$.

Yield analysis (for capsules made with IA OTMS-LUDOX):

$\mathrm{Si}\left(\mathrm{OC}_{2} \mathrm{H}_{5}\right)_{4}+4 \mathrm{H}_{2} \mathrm{O} \rightarrow \mathrm{Si}(\mathrm{OH})_{4}+4 \mathrm{EtOH}$

$\mathrm{Si}(\mathrm{OH})_{4} \rightarrow \mathrm{SiO}_{2}+2 \mathrm{H}_{2} \mathrm{O}$

1:1 $\mathrm{mol}$ ratio of TEOS:SiO, $1 \mathrm{~mL}$ TEOS $=0.93 \mathrm{~g}=0.0045 \mathrm{~mol}$

$0.0045 \mathrm{~mol}\left(\mathrm{SiO}_{2}\right)=0.27 \mathrm{~g}$ for $1 \mathrm{~mL}$ TEOS

$1 \mathrm{~g}$ of aqueous phase $+0.375 \mathrm{~g}$ OTMS-LUDOX $+0.27 \mathrm{~g} \mathrm{SiO}_{2}=1.645 \mathrm{~g}$ max. yield for $1 \mathrm{~mL}$ TEOS (ignoring extra water produced from TEOS condensation)

\begin{tabular}{|c|c|c|c|}
\hline TEOS $(\mathbf{m L})$ & Max. yield $(\mathbf{g})$ & Actual yield $(\mathbf{g})$ & \% yield \\
\hline 1 & 1.645 & 1.109 & 67.4 \\
\hline 1.5 & 1.781 & 1.300 & 73.0 \\
\hline 2 & 1.915 & 1.784 & 93.2 \\
\hline 3 & 2.185 & 2.190 & 100.2 \\
\hline
\end{tabular}

It is interesting that the \% yield increases with increased TEOS volume, showing a more robust shell is formed by incorporating all silica reactants and encapsulates the aqueous phase more efficiently. 


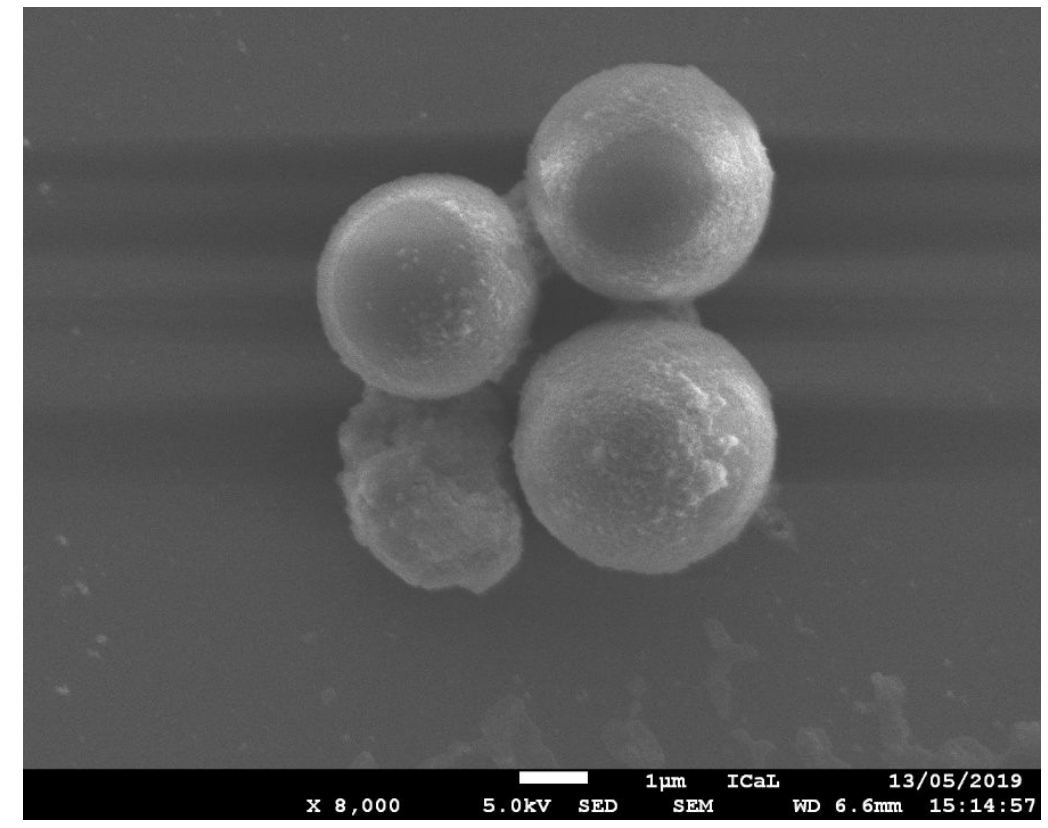

Figure S6. SEM images of capsules made with $5 \%$ wt IIn OTMS-LUDOX with $3 \mathrm{~mL}$ TEOS added. These large capsules often have areas of the shell with no coverage of OTMS-LUDOX, revealing the smooth inner $\mathrm{SiO}_{2}$ shell formed by TEOS condensation. Scale bar is $1 \mu \mathrm{m}$. 


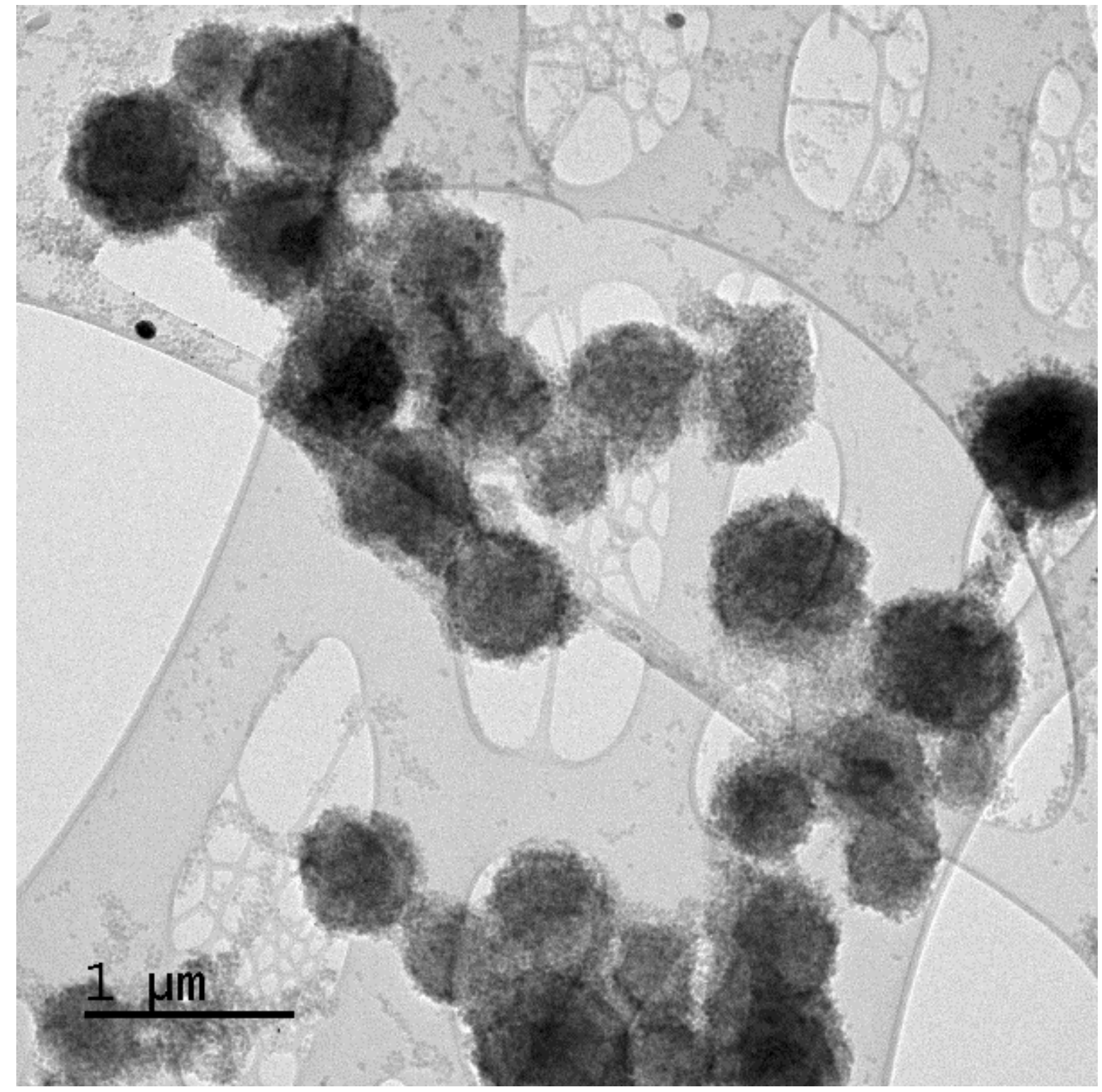

Figure S7. Enlarged version of Figure 4a. Note the 'halo' appearing for many capsules which is the inner shell deposited by TEOS condensation. 


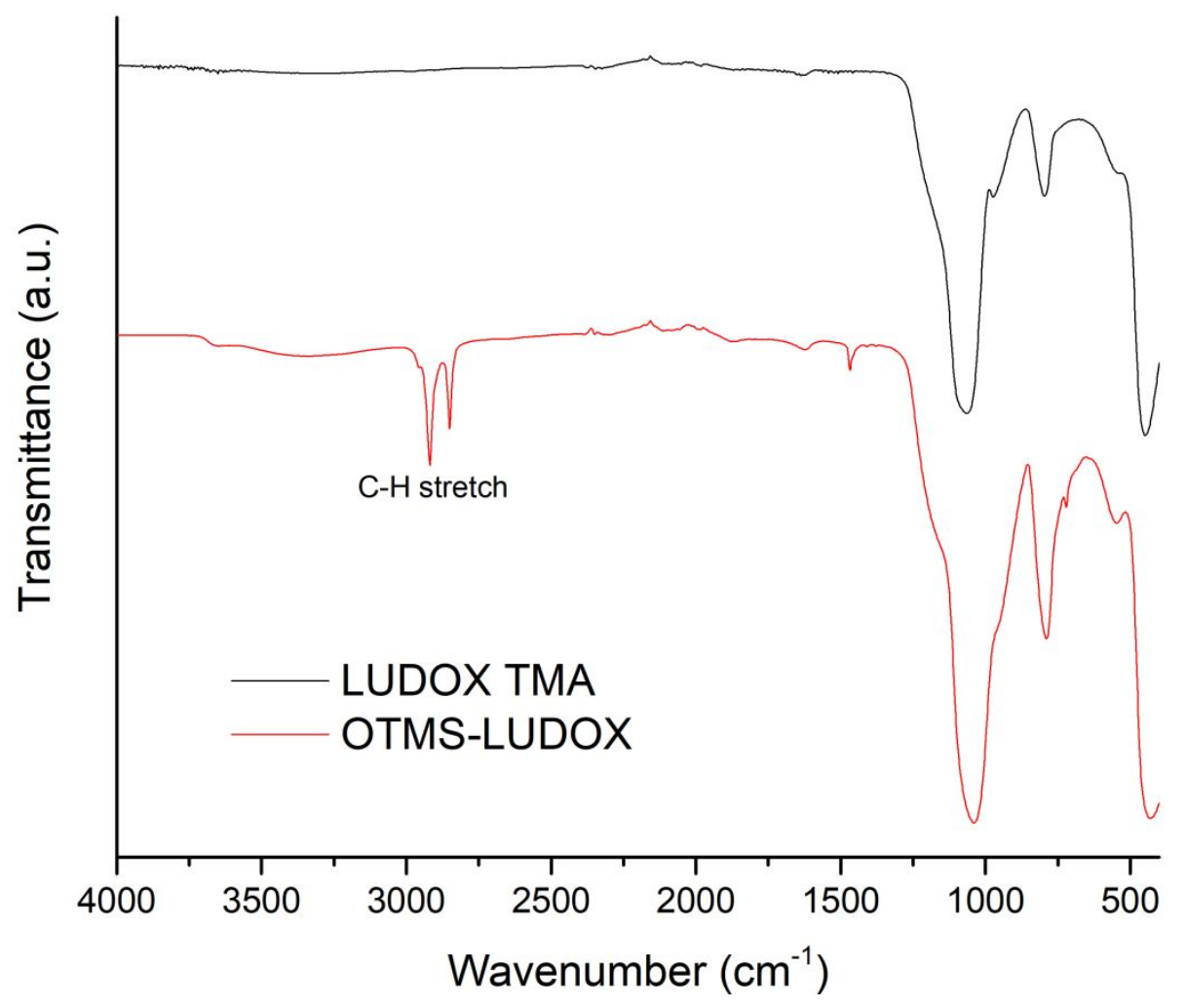

Figure S8. FTIR spectra for LUDOX TMA and OTMS-LUDOX. After reaction with OTMS, a strong C-H stretching peak appears in the spectrum at 2854 and $2924 \mathrm{~cm}^{-1}$ which is absent for unmodified LUDOX TMA.
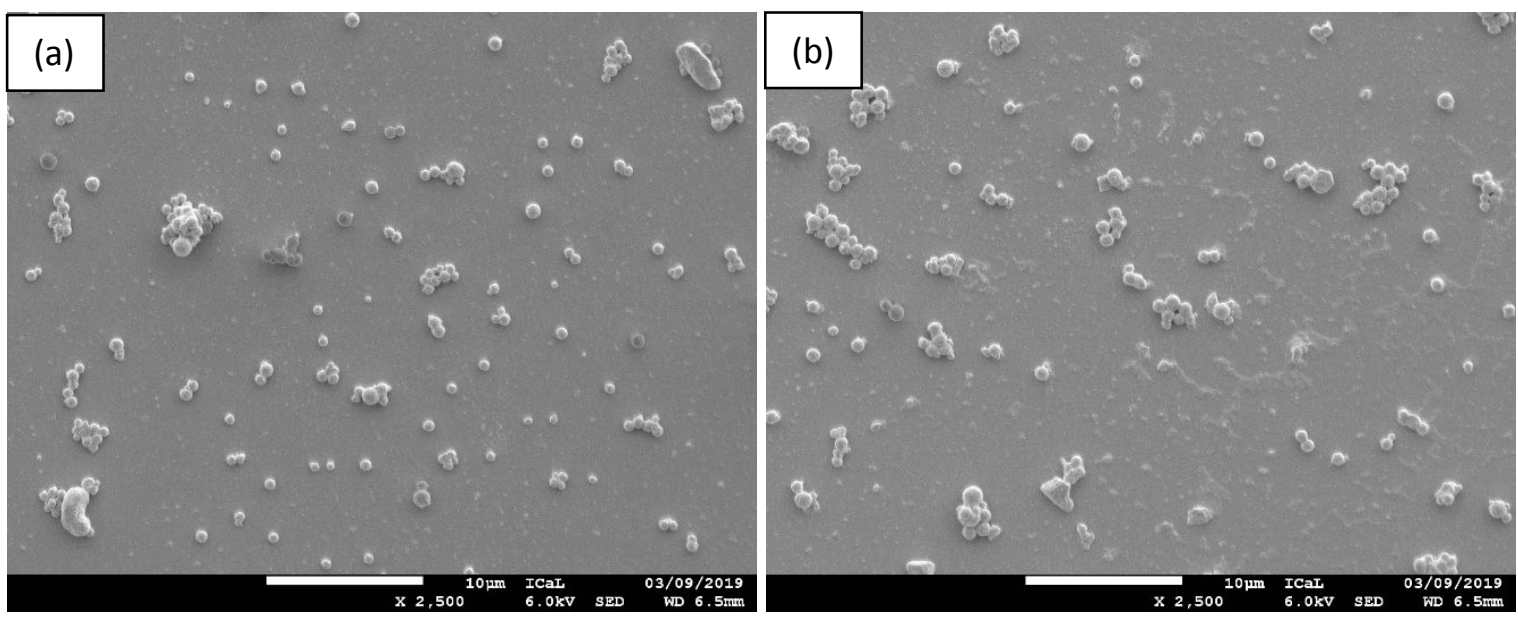

Figure S9. SEM images of RSS capsules made with (a) 10 min of sonication time and (b) 60 min sonication time. Scale bars are $10 \mu \mathrm{m}$. 

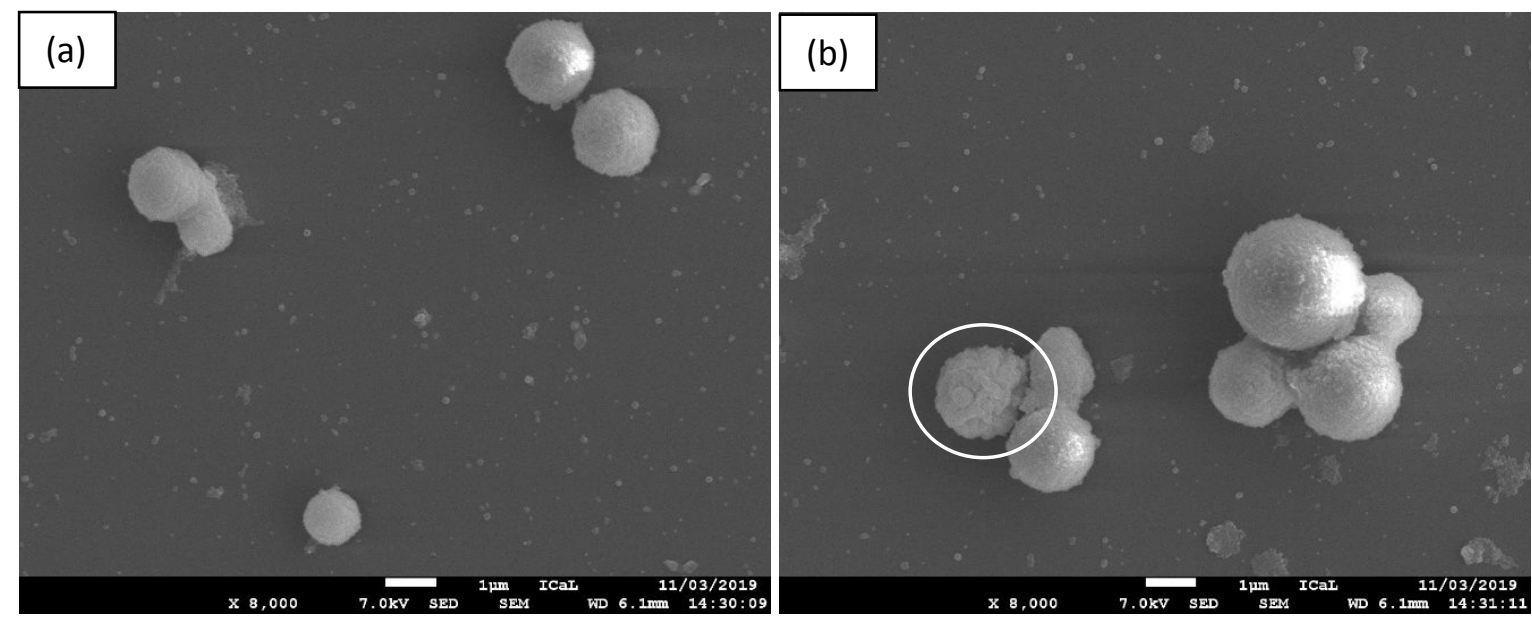

Figure S10. SEM images of RSS capsules with $2 \mathrm{~g}$ of $50 \% \mathrm{wt} \mathrm{Mg}\left(\mathrm{NO}_{3}\right)_{2} \cdot 6 \mathrm{H}_{2} \mathrm{O}$ solution as aqueous phase, with $2 \mathrm{~mL}$ TEOS and $2 \mathrm{~mL} \mathrm{HCl}$ added. Note the larger capsule sizes compared to the regular synthesis with $1 \mathrm{~g}$ aqueous phase, and the wrinkled capsule circled in (b). Scale bars are $1 \mu \mathrm{m}$. 